\title{
APPLICATION OF SOFTWARE IN THE DIAGNOSIS OF HEARING IMPAIRMENT
}

\section{Esad H. Mahmutović ${ }^{1}$ Husnija Hasanbegović}

\author{
Original scientific paper \\ DOI:10.21554/hrr.091715
}

University of Tuzla, Faculty of Education and Rehabilitation, Bosnia and Herzegovina

Received: 12.04 .2017

Accepted: 20.07.2017

\begin{abstract}
Aim of this paper was to examine effectiveness and efficiency of examination of hearing status of persons with hearing impairment in form of applicable diagnostic software, in relation to classical approach. Sample was comprised of 90 respondents and was formed out of two subsamples. First subsample was comprised of 45 students with hearing impairment with a degree of impairment of over $80 \mathrm{~dB}$, both genders, age from 6 to 15 years and without any other disabilities. Second subsample was comprised of 45 students (absolvents) from department of audiology. For data gathering, audiogram, applicable diagnostic software and scale for evaluation of attention and cooperation were used. Data was processed with descriptive analysis, McNemar and Wilcoxon tests. Results of the research confirmed that applicable diagnostic software provide more effective and more efficient diagnostic procedures for examining hearing status of persons with hearing impairment in relation to classical approach.
\end{abstract}

Key words: hearing status, effectiveness, efficiency, diagnostic software

\section{INTRODUCTION}

Hearing impairment in childhood represents serious problem from stand point of audiology, education and sociology.

Early and reliable diagnosis of hearing impairment is necessary in order to reduce eventual delays that could be caused by impairment and to reduce its negative impact to development (Grant, 2000; Yoshinaga-Itano, Coulter \& Thomson, 2001; Kennedy, 2006; American Academy of Pediatrics (AAP), 2007).

Different ways of conducting diagnostic procedures, from the aspect of procedure organization and technical support, have very important impact on setting clear and right diagnosis. Efficiency and effectiveness of those methods depend on duration, velocity of data gathering and evaluation, accuracy and precision of the data, velocity and method of archiving that data, velocity and method of data flow, level of general state of the respondent during the evaluation (attention, focus, and cooperation), ability of continual evaluation and tracking rehabilitation program realization.

According to Gillard, Bailey, and Nolan (2008), technology is truly everywhere and its widespread adoption and application has changed the way each and every one of us lives and makes a living in modern society.

Scientific activities, in last thirty years and more, conditions noticeable and frequent technological and technical improvements. Information technologies impact the knowledge in sense that it is becoming dynamic development resource, the driver of functional application of science aiming to discover new knowledge. Process of preparation, transmission and reception of information - knowledge, and manifestation of education and rehabilitation, seem unimaginable and almost impossible without information and communication technologies although traditional - pen and paper method is important if not dominant in these processes.

\section{${ }^{1}$ Correspondence to:}

Esad H. Mahmutović, University of Tuzla, Faculty of Education and Rehabilitation, Bosnia and Herzegovina

Univerzitetska 1, 75000 Tuzla, Bosnia and Herzegovina

Phone: +38761290780

E-mail: esad25@yahoo.com 
According to Yoshinaga-Itano (2004) and Nicholas and Geers (2006), technological improvement has significantly influenced diagnosis and treatment of paediatric hearing loss and provided better development of their listening and oral language skills.

Dornan (2010) emphasizes that significant technological developments have included newborn hearing screening, new objective diagnostic tests, digital hearing aids, cochlear implants and auditory signal processing. Along with these advancements, a confluence of research from many other sciences is occurring, creating previously unimagined options for the treatment of paediatric hearing loss.

New technologies in area of rehabilitation, listening and speech and their functionality of increasing earshot and better understanding of speech have significantly contributed to better hearing and oral communication of deaf persons, which from aspects of functionality, audiology and speech-language aspect implies successful socialization, education and professional emancipation of deaf persons in society. Technical and technological advances in electroacoustic, with an emphasis on manufacturing and application of modern hearing apparatus, demands application of carefully selected methods and programs in very complex and responsible professional work with deaf persons. At the same time, higher forms of cognitive abilities are stimulated and that means more efficient influence on general development of personality (Kurtagic \& Hasanbegovic, 2004).

Considering that information technology is already a reality for professionals and for persons with hearing impairments, especially in area of evaluation of hearing status and speech-language development, which would improve efficiency and effectiveness of diagnostic in harmony with real technological capabilities, it can significantly improve whole educationrehabilitation process.

Developing software for deafness diagnosis, using model equations, numerical schemes, Dunmade, A. O., Dunmade, A. D., Taiwo, Tomori, and Komolafe, (2009) emphasize importance of computer technologies in the process of diagnosis, claiming that this software is an important tool for medical practitioner - otorhinolaryngologists because it helps in determining severity of deafness in each individual patient case.

Dolinay, Zlinksy, and Vasek (2005) have developed computer program that aids doctors and audiologists for automatic calculation of percentage of hearing loss per Fowler-Sabine, calculation of average hear- ing loss and can display audiometric curve, which can alongside others, be stored as a picture and can be archived for future queries.

Aim of this research was to examine effectiveness and efficiency of hearing status examination of persons with hearing impairment in form of applicable diagnostic software in relation to classical approach. We have assumed that there is significant advantage in favor of applying diagnostic software in effectiveness of diagnostic procedures, considering hearing status and efficiency of the procedures considering evaluation time, attention and cooperation of respondents.

\section{METHODS}

\section{Sample of respondents}

Research was conducted on the sample of 90 respondents, which has been formed from two subsamples, for the needs of the research. First subsample, which was used to examine effectiveness and efficiency of diagnostic software, in relation to classical approach, was formed of 45 respondents from the population of students with hearing impairments based on following criteria: degree of impairment above $80 \mathrm{~dB}$, age from 6 to 15 years without any other disabilities. Second subsample was comprised of 45 students (absolvents) from the department of audiology. Subsample of absolvents was used to determine: time and accuracy of developing audiogram, kind of hearing impairment, time and accuracy of calculation of the degree of hearing impairment and percentage of hearing loss according to Fowler Sabine.

\section{Measuring instruments and sample of variables}

For conducting this research following tools were used: audiogram, diagnostic software and numerical scale for evaluating attention and cooperation of respondents. Audiogram was used in two different forms (mediums): first, classic (pen and paper) form, where diagnostic form with audiogram and scale for evaluating percentage of hearing loss Fowler-Sabine, was on paper; second - digital form, where whole material was stored into form of applicable diagnostic software. Diagnostic software represented digitaldiagnostic product, which was developed for needs of this research and was used for diagnostic purposes, but it can be also used in rehabilitation purposes in the process of rehabilitation of speech and listening. 
It was arranged in form of diagnostic procedures (measuring instruments) and database for storing, querying and printing stored evaluation results through findings, opinions or, if needed, in some other form. Program has four segments, which, combined together comprise unique diagnostic whole. When it comes to evaluating hearing status, it has been programmed to enter data into two tables that appear on monitor for hearing thresholds ( $\mathrm{dB}$ in value) acquired by audio-metrics, and based on those, program will, by the press of a button, draw according curves of areal and bone conductivity, calculate degree of hearing impairment and percentage of hearing loss according to Fowler-Sabine. Patter appears on the monitor, showing findings of evaluation results, with an empty column for descriptions and audiologist's opinion.

Variables from tonal audiogram that were used for effectiveness evaluation were: degree of hearing impairment accuracy, percentage of hearing loss according to Fowler-Sabine accuracy, and for efficiency: time needed to evaluate hearing status. Numerical Scale for attention and cooperation evaluation during examining effectiveness and efficiency was scale of 10 degrees on which examiners graded these two criterions. Variables sample from this Scale were: attention during evaluation and cooperation during evaluation.

\section{Research conducting manner}

Examining hearing status in a classical manner was conducted by students of audiology were given tasks based on decibel values, that were gather from audiometrics from deaf and heavy hearing impaired persons. Students had to develop an audiogram, examine the kind of hearing impairment and calculate degree of hearing impairment and percentage of hearing loss according to Fowler-Sabine. Results were entered on special for, including beginning time and ending time. With examination via diagnostic software, same students were entering decibel values into the program and it automatically showed results. Results for efficiency with classical approach, which are time dependent, team member, had to manually enter results, while with software approach it was done automatically. Other variables for efficiency evaluation (attention and cooperation), in both evaluation manners, and based on observing respondents while examination was conducted, were evaluated subjectively by every team member. Results were obtained using evaluation scale and average result was taken into account.

\section{Data processing methods}

SPSS for Windows was used to process data. In order to make decision on conducting adequate tests and analysis, Shapiro-Wilk test $(\mathrm{N}<50)$ was used for evaluation of normal distribution. Data was processed by descriptive analysis and tests of non-parametric statistics. Frequencies distribution, percentages, and basic statistical parameters were established. For differences in results of evaluation of hearing status testing, effictiveness of diagnostic program i.e. evaluating accuracy of results McNemar test was used. Wilcoxon test was used to test efficiency of diagnostic procedures i.e. significance of differences of evaluation of average time of diagnostic procedures, attention and cooperation of deaf and heavy hearing impaired students.

\section{RESULTS AND DISCUSSION}

Timely, adequate and continuous evaluation and treatment of children and older persons with hearing impairment are important for every individual, in person development and affirmation and for the community. Yoshinaga-Itano (2003) emphasizes that quality of medical, audiological, and educational intervention services most likely impacts developmental outcome. New technical and technological accomplishments should be used to constantly aid and track, in order to reduce possibility of lagging behind in development of persons with hearing impairment, and with that unnecessary expenses that community is exposed to in order to take care of these individuals.

The Better Hearing Institute in the U.S. made a similar estimate of the societal costs. BHI estimated the annual cost of untreated hearing loss to be US\$56 billion in the United States and 92 billion euro in the EU, mainly due to lost productivity. According to the study, the estimated societal costs of not treating hearing loss in Europe in the years 2001 to 2005 amounted to a staggering 400 billion euro (Garrett, 2010).

Evaluation of all segments of hearing status and speech and language development should be continuous process. Reason for that is application of treatments that are intended to continually cause change in all development aspects, which is, why it is important to do checks, tracking and evaluation on them all the time. Continuous tracking gives insight into levels of development, but it also evaluates treatments that should me continued, modified or completely changed. 
Procedures in diagnostic process, besides that, cannot become purpose of their own. They too, need to be checked and questioned regarding applied contents, timeliness, evaluation manners, effectiveness and efficiency of conducting in all individual development areas.

\section{Research results of effectiveness diagnostic proce- dures when evaluating hearing status}

In Table 1, frequency distribution and percentage of results of hearing status research, for variables accuracy of degree of hearing impairment evaluation and percentage of hearing loss according to Fowler-Sabine, for evaluation of deaf and heavy hearing impaired respondents in two different ways of evaluation, are shown. In both programs, respondents' frequency, on both variables is in favor of diagnostic software, and not in favor of classical approach. Evaluating with diagnostic software, complete accuracy was observed for evaluation of hearing status (without repetition), with all respondents (45 respondents or 100\%), in both variables (hearing impairment degree accuracy and percentage of hearing loss according to FowlerSabine accuracy). Classical approach, in first evaluation of hearing status, in degree of hearing impairment, was accurate for 41 respondents or $91 \%$, and wrong for 4 respondents of $8.9 \%$, while in percentage of hearing loss according to Fowler-Sabine accuracy was observed for 33 evaluations or $73.3 \%$ and inaccurate for 12 or $26.7 \%$, which is large and significant difference if evaluation is not repeated.

Table 1 Degree of hearing impairment and percentage of hearing loss according to Fowler-Sabine evaluations

\begin{tabular}{lccccc}
\hline \multicolumn{1}{c}{ Variables } & Response & \multicolumn{2}{c}{ Classical } & \multicolumn{2}{c}{ Software } \\
& & f & \% & f & \% \\
\hline Degree of hearing impairment & Yes & 41 & 91.1 & 45 & 100.0 \\
evaluation accuracy & No & 4 & 8.9 & 0 & .0 \\
\hline Percentage of hearing loss FS & Yes & 33 & 73.3 & 45 & 100.0 \\
evaluation accuracy & No & $\mathbf{1 2}$ & $\mathbf{2 6 . 7}$ & 0 & .0 \\
\hline
\end{tabular}

To test differences in evaluation results for hearing status, when evaluating effectiveness of diagnostic software, i.e. accuracy of evaluation results, McNemar test was used for dependent samples. Test results have shown that differences got from descriptive analysis are statistically significant, with percentage of hearing loss according to FowlerSabine $(\mathrm{p}=.00)$ in favor of diagnostic software, and for degree of hearing impairment evaluation accuracy we have no statistically significant difference $(p=.13)$, applying two different evaluation manners (Table 2).

Table 2 McNemar's test results

\begin{tabular}{lcc}
\hline Variables & $\mathbf{N}$ & $\mathbf{p}$ \\
\hline Degree of hearing impairment evaluation accuracy & 45 & .13 \\
Percentage of hearing loss FS evaluation accuracy & 45 & $\mathbf{. 0 0}$ \\
\hline
\end{tabular}

Evaluation of degree of hearing impairment is mostly used for selecting adequate hearing apparatus and classification of respondents for developing rehabilitation program for speech and listening, while percentage of hearing loss evaluation is used to determine degree of invalidity in order for person to obtain educational and social rights. Every mistake in accurate evaluation for respondents in first phase can cause delay of adequate professional action at best, and rest of the consequences is unpredictable.
Based on the presented research results, we can clearly see significance of software enhancements in diagnostics. Humans are, in such evaluation, prone to errors, which were proven during the research.

Establishing listed parameters, via diagnostic software, on basis of formulas and values from table for evaluating percentage of hearing loss according to Fowler-Sabine, in relation to classical methods (even using calculator), shows advantages that should influence better diagnostics. 
That should be taken into account, as well as that in evaluation results, no statistically significant differences were observed when evaluating degree of hearing impairment.

According to Dunmade et al. (2009), in the process of developing a software, the scientists and engineers study various are as and techniques of designing software with a view to efficiently and effectively sorting and retrieving information. Many factors must be put into consideration when writing a software. For instance, since computers have only a limited amount of memory, the designers must limit the number of features included in the program so as not to exceed the requirements of the system it is designed for. This software was written using Visual Prolog. For this work, the PTA Test is used as a means of identifying and classifying the severity and type of deafness in a patient, and suggesting a likely solution to the problem. Using the model equations, a numerical scheme was used to develop a software capable of diagnos- ing deafness. It is important to note that this software helps the medical practitioner- the otorhinolaryngologist in his task of determining the severity of deafness in each individual patient case.

\section{Research results of efficiency of diagnostic proce- dures when evaluating hearing status}

For comparing the results acquired by two different ways of evaluation, in Table 3 are shown basic statistical parameters for efficiency of diagnostic procedures evaluation. Brief information for every variable for evaluation of time needed for evaluating hearing status, attention and cooperation, can be observed.

Insight in results shows that inside every individual evaluation manner, there are significant deviations of respondents in answers for every variable, and there are significant differences of basic statistical parameters between two evaluation manners.

Table 3 Basic statistical parameters for determining efficiency of diagnostic procedures

\begin{tabular}{lccccc}
\hline Variables & Evaluation type & Min & Max & M & SD \\
\hline \multirow{2}{*}{ Attention } & Classical & 3.25 & 7.00 & 5.34 & 1.13 \\
& Software & 8.00 & 10.00 & 9.27 & .64 \\
\multirow{2}{*}{ Cooperation } & Classical & 2.00 & 7.00 & 5.26 & 1.24 \\
& Software & 8.00 & 10.00 & 9.33 & 0.64 \\
\multirow{2}{*}{ Time } & Classical & 6.00 & 21.00 & 11.22 & 3.59 \\
& Software & 3.00 & 5.00 & 3.82 & .58 \\
\hline
\end{tabular}

Wilcoxon test was used to test significance of the difference in results of evaluating objective parameters of efficiency (duration of diagnostic procedure and time focused on contents during evaluation), acquired by two different manners of evaluation and testing differences of results on the scale of subjective evaluation of attention and cooperation of deaf and heavy hearing impaired persons by audiologists. Establishing significance was done for: time needed to determine hearing status $(Z=-5.85)$, evaluating attention $(Z=-5.86)$ and cooperation $(Z=-5.85)$, where every variable has statistically significant difference in favor of diagnostic software on the level of significance $p=.00$. Value of impact magnitude ( $r$ ) for these differences, according to Koenov criterion is large, $r=-.62$ (Table 4).

According to Dolinay, Zlinsky, and Vasek (2005), without utilization of computers the calculation of the Fowler number is rather slow. It is not because it would be complicated. The whole algorithm is to find measured value in a table and then use simple equation to get final result. In present, still a large number of doctors do this manually or use simple programs which create another request: patients already have electronic medical history record and it would be suitable to save the results from audiometric investigation into this record also. Not only Fowler number but all measured hearable intensity should be saved. For better understanding, let's describe the doctor's routine during investigation. First they have to do measurement, and then retype whole data into a program to calculate Fowler number. After that they have to retype data into patient history record. The purpose of this work is to save doctor's time, at least to omit one data retyping. 
To reach that purpose we created a simple program. Measured data should be typed into this program, which is instantly calculating Fowler number. If doctor requires graphical output, program must be able to show audiogram and also save it into the file. Program also must be able to transfer data into extern database program. In cooperation with practical doctors the application has been created. The program is $\mathrm{C}++$ language, dialog based application. (Kruglinski, 1997). When program starts the main window is shown. The left side of the window contains controls for "Tuning fork investigation" with pre-set default settings. In this case default means patient without problems. This investigation is mostly used as a preventive. If the patient is without complications subsequent investigation are not needed and in this case doctor just need to press button to transfer results into patient's database record. If audiometric investigation is required, than doctor or skilled nurse will type measured data from audiometer into program. Those data can also be transferred into patient record. When audiometric investigation is done and all data are entered the audiogram can be shown or saved as an image file into shared directory. Supported file formats include: bmp, jpg, gif tiff, pnf. If also patient age is entered in the left bottom part of the main window, the patient is categorized into possible risky class.

As was already mentioned the program has several fundamental outputs. First is Fowler number as a result of audiometric investigation. Next output is audiogram and classification diagram based on Fowler number and patient age. The program allows doctors to simply and quickly enter the data obtained during patient hearing examination and automatically calculate the hearing loss coefficient by Fowler for one or both ears, calculation of middle value sound intensity in decibels from all entered frequencies air and bonds transition for left and right ear or both together. Program also provides tool for preventive hearing investigation of persons working in hearing-damage risky places. This tool according to patient age and entered measured volumes places the patient into risky groups. This placement can be shown in simple diagram. The diagram can be saved as an image file. All diagrams if needed can be searched depending on patient identification number or his her insurance number. If pre-set information are filled program is able to create complete after-examination record. For audiometric investigation, when all necessary information is typed, program offers the possibility to create audiometric curve, which can be saved and also later searched by above mentioned patient data. If the curve fulfills all requirements, such as number of necessary frequencies and so on, it can be imported into image module of ambulant program or saved in program archive and later use as a proof of investigation for insurance company.

In favor to those research goes Larson's statements (2000), who emphasizes that although most language teachers today stress the development of oral skills in their teaching, it is very difficult for them to find time to assess these skills. The general consensus in foreignand second-language education is that oral skill development is a high priority, indeed in many cases, the top priority. If, in fact, speaking is emphasized, it should also be tested periodically. However, assessing oral skills requires a significant commitment of time and energy on the part of language teachers. In an effort to mitigate this testing burden, testing software has been developed that allows teachers to construct computerized oral tests, to administer them, and to assess students' responses with relative ease. Using this kind of software in conjunction with an appropriate scoring technique, teachers can assess their students' oral performance on a relatively frequent basis with a minimal loss of classroom time.

Table 4 Wilcoxon test rang results when examining efficiency of diagnostic procedures

\begin{tabular}{lccc}
\hline \multicolumn{1}{c}{ Variables } & $\mathbf{Z}$ & $\mathbf{p}$ & $\mathbf{r}$ \\
\hline Time needed to determine hearing status & $-5,85$ & $\mathbf{. 0 0}$ & -.62 \\
Attention during evaluation & $-5,85$ & $\mathbf{. 0 0}$ & -.62 \\
Cooperation during evaluation & $-5,86$ & $\mathbf{. 0 0}$ & -.62 \\
\hline
\end{tabular}

All variables, that are related to efficiency of diagnostic procedures, and which have statistically significant differences in favor of application of diagnostic software in relation to classical evaluation, are a proof for need of digitalization of diagnostic procedures in audiology. Variables that are related to time, impact the most important factor in education-rehabilitation process, and that is "acting early", which along with adequate scientific research and practical application has provided good results with efficiency (reduction in time) and effectiveness (accuracy of results) of diagnostic procedures. 


\section{CONCLUSION}

Diagnostic software provide more effective and efficient application of diagnostic procedures for examining hearing status of persons with hearing and speech impairments compared to classical approach. Significantly better effectiveness of conducting diagnostic procedures in favor of diagnostic software has been confirmed with evaluating percentage of hearing loss according to Fowler-Sabine and degree of hearing impairment, while presence of significantly better efficiency is confirmed on evaluated indicators: time, attention and cooperation of students during evaluation of hearing status.

\section{REFERENCES}

American Academy of Pediatrics (AAP). (2007). Position Statement: Principles and Guidelines for Early Hearing Detection and Intervention Programs. Pediatrics, 120, 898 921. doi:10.1542/peds.2007-2333

Dolinay, V., Zlinsky, V. \& Vasek, V. (2005). Software utility for processing of hearing investigation result. Annals of $D A A A M$ \& Proceedings. Retrived from http://www.thefreelibrary.com/Software+utility+for+processing + of + he aring+investigation+results.-a0176688296

Dornan A. D. (2010). Outcomes for Young Children with Hearing Loss in an Auditory-Verbal Therapy Program. A thesis submitted for the degree of Doctor of Philosophy at the University of Queensland in November 2010, School of Health and Rehabilitation Sciences. Retrived from http://espace.library.uq.edu.au/view/UQ:237839

Dunmade, A. O., Dunmade, A. D. Taiwo O. A., Tomori A. R. \& Komolafe T. M. (2009). A Software System for Diagnosis and Classification of Deafness. European Journal of Scientific Research, 25(4), 597-605. Retrived from http://www.eurojournals.com/ejsr_38_2_05.pdf

Garrett, K. (2010). The Real Cost Of Hearing Loss. Timpanogos Hearing \& Balance. Retrived from http://utahhearingaids.com/real-cost-hearing-loss/
Gillard, S. Bailey, D. \& Nolan, E. (2008). Ten Reasons for IT Educators to be Early Adopters of IT Innovations. Journal of Information Technology Education, 7, 21-33. Retrived from http://jite.org/documents/Vo17/JITEv7p021033Gillard257.pdf

Grant, R. (2000). The case to find universal newborn hearing screening in New York State, Int. J. Pediatr. Otolaryngol, 54, 8-9. Retrived from http://www.childrenshealthfund. org/sites/default/files/NewbornHearingNYS.pdf

Kennedy, C. R., McCann D. C., Campbell, M. J., Law, C. M., Mullee, M, Petrou, S., Watkin, P., et al. (2006). Language ability after early detection of permanent childhood hearing impairment. $N$ Engl J Med, 354(20), 2131-2141. doi: 10.1056/NEJMoa054915

Kurtagić, I. \& Hasanbegović H. (2004). Procesi učenja govora $\mathrm{i}$ jezika kod gluhih u postoperativnoj rehabilitaciji. [The process of learning speech and language for the deaf in postoperative rehabilitation.] Defektologija, 11. 15-20

Larson, W. J. (2000) Testing Oral Language Skills via the Computer, CALICO Journal 18(1), 53-66. doi: http://dx.doi. org/10.11139/cj.18.1.53-66

Nicholas, J.G. \& Geers, A.E. (2006). Effects of early auditory experience on the spoken language of deaf children at 3 years of age. Ear and Hearing 27(3), 286-298. doi: 10.1097/01.aud.0000215973.76912.c6.]

Yoshinaga-Itano, C., Coulter, D \& Thomson, V. (2001). Developmental outcomes of children with hearing loss born in Colorado hospitals with and without universal newborn hearing screening programs, Semin Neonatal, 6, 521-529. Retrived from http://www.sciencedirect.com/ science/article/pii/S1084275601900752

Yoshinaga-Itano, C. (2003). Early intervention after universal neonatal hearing screening: Impact on outcomes. Mental Retardation and Developmental Disabilities Research Reviews, 9(4), 252-266. doi: 10.1002/mrdd.10088

Yoshinaga-Itano, C. (2004). Levels of evidence: Universal newborn hearing screening (UNHS) and early hearing detection and intervention systems (EHDI). Journal of Communication Disorders, 37(5), 451-465. doi:10.1016/j. jcomdis.2004.04.008 